\title{
Pattern in the co-occurrence of fishes inhabiting the coral reefs of Bonaire, Netherlands Antilles
}

\author{
Peter J. Auster ${ }^{\mathrm{a}}$, Brice X. Semmens ${ }^{\mathrm{b}}$ \& Kimberly Barber ${ }^{\mathrm{a}}$ \\ ${ }^{\mathrm{a}}$ National Undersea Research Center and Department of Marine Sciences, University of Connecticut at Avery \\ Point, Groton, CT 06340, U.S.A. \\ ${ }^{\mathrm{b}}$ Department of Biology, University of Washington, Box 351800, Seattle, WA 98195, U.S.A.
}

Received 12 August 2004

Accepted 11 May 2005

Key words: visual census, diver survey, similarity matrix, habitat, behavior, reef fish

\section{Synopsis}

We conducted an analysis of species associations using fish diversity and abundance surveys conducted in Bonaire Marine Park by recreational divers. We used data from the REEF (Reef Environmental Education Foundation) Fish Survey Project to compute Bray-Curtis similarity coefficients for all species pairs for the 100 most abundant species. We quantified relationships between species using hierarchical agglomerative clustering and non-metric multidimensional scaling (MDS) of the matrix of Bray-Curtis similarity coefficients. We identified three clusters of species from the analysis. MDS results showed species clusters occupied distinct regions across a continuous gradient of species in two-dimensional space, rather than form distinct clusters. While differences in habitat requirements can explain some of the pattern in pairwise species interactions, these results suggest that there are significant direct and indirect behavioral interactions mediating the distribution and abundance of species. Studies conducted to elucidate patterns of species-habitat relationships have been central to conservation planning for marine protected areas (MPAs). However, the role of behavioral interactions between species driving the dynamics of species composition within MPA networks, designed for representation of biological diversity, should be considered when selecting sites in order to be effective.

\section{Introduction}

Developing an understanding of pattern in the cooccurrence of species in space and time has been central to studies investigating factors that mediate the structure of communities and distribution of species (Diamond 1975, Gotelli 2000, Lizaso et al. 2000). From an applied perspective, understanding such patterns is a critical step in developing strategies for conserving biological diversity. Interspecific interactions can mediate the distribution and abundance of reef fish (Hixon \& Carr 1997). Additionally, while coral reef fish communities have high species diversity overall, many species have considerable habitat specificity (Garpe \& Ohman 2003). Thus, identifying species associations and the interactions and habitat preferences that drive them is the first step toward gaining an improved understanding of how fish communities are assembled at small spatial scales.

We used the Reef Environmental Education Foundation (REEF) Fish Survey Project database $(\text { REEF 2001) })^{1}$ from the island of Bonaire, Netherlands Antilles, to quantify patterns in the

\footnotetext{
${ }^{1}$ REEF. 2001. Reef Environmental Education Foundation web site address www.reef.org, date of download 5 February 2001.
} 
co-occurrence of pairs of reef fish species. After identifying significant species relationships based on cluster analysis, we used a depth-weighted classification scheme to determine if associations were predictable based on species-specific depth affinities. Finally, we binned species into trophic guilds to determine if there were differences in functional group representation between major species clusters. The overall objective of this study was to develop an initial characterization of pairwise species relationships of the coral reef fishes off Bonaire. These results will aid in developing future studies to better understand the role of species interactions in community assembly.

\section{Methods}

Bonaire is located approximately $100 \mathrm{~km}$ off the coast of Venezuela in the Netherlands Antilles. The main island is $56 \mathrm{~km}$ in length and $11 \mathrm{~km}$ wide. Klein Bonaire is a small island off the leeward side of Bonaire. Both islands are surrounded by narrow fringing reefs. The southern leeward side of Bonaire has a nearly continuous double reef complex (Van Veghel 1997).

Recreational divers using the roving diver technique (i.e., a random swim approximately confined to an area with a radius of $100 \mathrm{~m}$ ) collected data on reef fish species composition and abundance (Schmitt \& Sullivan 1996). Only survey records collected during daylight hours by divers rated as "expert" in fish identification (i.e., based on REEF training and experience) were used in this analysis. We extracted data from the top 100 most abundant species, from the years 1993-2001, and included only data from sites classified as reef habitats (excluding seagrass, sand, rubble, artificial structures, and open water). These criteria produced 1380 individual surveys from 107 sites for analysis. For each survey divers recorded the abundance of all positively identified species in four broad categories (i.e., single $=1$, few $=2-10$, many $=11-100$, and abundant $>100$ ). In order to contrast relationships of species pairs based on abundance, we converted scores from the database to the minimum abundance value per category (i.e., not seen $=0$, single $=1$, few $=2$, many $=11$, abundant $=101$ ). We used minimum abundance as a proxy for actual abundance in order to obtain a first-order measure of the strength of pairwise interactions.

We computed Bray-Curtis similarity coefficients for all species pairs from the 1380 surveys without data transformation or standardization as numerical abundances were based on a fixed set of abundance categories. The Bray-Curtis similarity procedure provides a method of quantifying the similarity of species occurrences within sets of samples. A value of 0 indicates complete dissimilarity in co-occurrences (e.g., species A never occurs with species B) while a value of 100 indicates complete similarity in distribution (e.g., species A always occurs with species B). The interceding values allow us to compare the relative strengths of relationships between the occurrences of species pairs. We used hierarchical agglomerative clustering of the Bray-Curtis matrix, using the complete linkage method of joining species, to group species based on similarity relationships. Non-metric multidimensional scaling (MDS) was used to validate patterns in species relationships found using the clustering procedure and to illustrate the relationships between species in two-dimensional space. The MDS procedure was computed with 10 random restarts to reach a minimum stress value. We used the PRIMER software package to produce the Bray-Curtis matrix and conduct the multivariate analyses (Clarke \& Gorley 2001).

In order to explore possible relationships between cluster group membership and habitat, we analyzed depth related differences in the distribution of species groupings assigned from the cluster analysis. Although survey depth is the only quantitative habitat characterization reported on REEF surveys, it is an appropriate gross habitat metric because important abiotic factors (e.g. light penetration, temperature) tend to co-vary with it. In considering 16 different sitelevel habitat characteristics, Semmens \& Auster (2004) found that survey depth was the best predictor of fish assemblage composition at sites throughout the Caribbean. A depth category (values of $0-13$ in whole numbers) was reported for each survey (i.e., $0=$ surface, $1=<10 \mathrm{ft}$, $2=10-19 \mathrm{ft}, \quad 3=20-29 \mathrm{ft}, \ldots, 13=120-129 \mathrm{ft})$. We calculated a weighted depth index (WD) for each species as 
$\mathrm{WD}=$

$\sum$ (species abundance $*$ survey depth category)

$/ \sum$ species abundance

WD values for all species were normally distributed (Anderson-Darling normality test, $p>0.05$ ). We compared WD values in each cluster group using an ANOVA to determine if differences in depth between species groups could explain the pattern in the groupings. Paired t-tests were used to test for significant differences between the three cluster groups.

In order to explore the relationships of species in each cluster group based on functional roles, we assigned a trophic guild (i.e., herbivore, planktivore, browser, microinvertivore, macroinvertivore, piscivore; Table 1) to each species based on summaries of trophic status in Bohnsack (2002) and Randall (1967). To test the hypothesis that each cluster group contained constant proportions of species within trophic guilds, we compared the differences in guild representation between groups by using $\chi^{2}$ goodness-of-fit tests (Wilson 1989, Feeley 2003). Species that were originally assigned to multiple trophic guilds were subsequently assigned to a single major group (except we combined micro- and macro-invertivores), based on prey preferences of adults, to avoid violating assumptions of the goodness-of-fit test due to zeros in the data matrix . Each cell of the $3 \times 7$ matrix contained the percentage of species in the particular guild for the particular cluster group, rounded to the nearest whole number.

\section{Results}

The distribution of Bray-Curtis coefficients from the matrix of species pairs (4950 pairs) showed that more than $50 \%$ were within the first (lowest) quartile and $94 \%$ were within the first two quartiles (Figure 1). This pattern demonstrates that there were a significant number of dissimilarities in species co-occurrences of the most abundant species at the scale of diver surveys, although not fully exclusive (e.g., while species A and species B occur together, they do so less than expected). The cluster analysis showed that species grouped into three clusters at a similarity level of approximately $10 \%$ (Figure 2). Table 1 lists the species in each group. MDS results showed species groups from the cluster analysis occupied distinct regions across a continuous gradient of species in two-dimensional space, rather than form distinct and separate groups (Figure 3 ).

The comparison of WD values for each group showed that there were significant differences between groups (ANOVA $p<0.001$, df 2, 97; Figure 4) and mean WD values increased across groups from A to C. However, paired $t$-tests, adjusted for multiple comparisons, indicated that while the WD values of groups A and B were statistically similar $(p=0.33)$, group $\mathrm{C}$ was significantly different from both A and B $(p<0.001$ and $p<0.005$ respectively).

All trophic guilds were represented in each of the clusters (Table 1). However, the proportions of trophic guilds within cluster groups A, B, and C were significantly different between all groups (Table 2). The proportion of herbivores and planktivores declined across groups from $\mathrm{A}$ to $\mathrm{C}$ while the proportions of browsers, micro- and macro-invertivores (but not those taxa classified as mixed invertebrate predators), and piscivores all increased. These trends were correlated with the increasing mean depth across the cluster groups.

\section{Discussion}

Our analysis indicates that there are a large number of pairwise species associations with a range of dissimilarity that, in part, could be mediated by direct or indirect species interactions (i.e., competition, predation). Both multivariate approaches were in general agreement regarding the consistent relationships of component species such that those in each group would tend to co-occur and those across groups would have lower probabilities of occurring together (at the spatial scale of diver surveys). Our analysis of species-depth associations demonstrated that cluster differences could at least partially be explained by depth-associated habitat characteristics, although only one of the clusters differed significantly in average WD scores. For example, planktivores within group A (i.e., brown and blue chromis, Creole fish, sergeant major) are all part of a feeding guild that aggre- 
Table 1. Species list by cluster group. Species codes correspond the numbers in the MDS plot.

\begin{tabular}{|c|c|c|c|}
\hline Species code & Scientific name & Common name & Trophic level \\
\hline \multicolumn{4}{|l|}{ Cluster a } \\
\hline 52 & Abudefduf saxatilis & Sergeant Major & $P$ \\
\hline 206 & Acanthurus bahianus & Ocean Surgeonfish & $\mathrm{H}$ \\
\hline 204 & Acanthurus coeruleus & Blue Tang & $\mathrm{H}$ \\
\hline 131 & Bodianus rufus & Spanish Hogfish & $\mathrm{Mi}$ \\
\hline 167 & Canthigaster rostrata & Sharpnose Puffer & $\mathrm{H}, \mathrm{B}$ \\
\hline 42 & Chromis cyanea & Blue Chromis & $\mathrm{P}$ \\
\hline 43 & Chromis multilineata & Brown Chromis & $\mathrm{P}$ \\
\hline 215 & Clepticus parrae & Creole Wrasse & $P$ \\
\hline 79 & Coryphopterus glaucofraenum & Bridled Goby & $\mathrm{H}$ \\
\hline 87 & Coryphopterus lipernes & Peppermint Goby & $\mathrm{H}$ \\
\hline 83 & Coryphopterus personatus/hyalinus & Masked Goby/Glass Goby & $\mathrm{P}$ \\
\hline 81 & Gnatholepis thompsoni & Goldspot Goby & $\mathrm{H}$ \\
\hline 10 & Gramma loreto & Fairy Basslet & $\mathrm{P}$ \\
\hline 113 & Haemulon chrysargyreum & Smallmouth Grunt & $\mathrm{Ma}$ \\
\hline 108 & Haemulon flavolineatum & French Grunt & Ma \\
\hline 218 & Halichoeres bivittatus & Slippery Dick & $\mathrm{Mi}, \mathrm{Ma}$ \\
\hline 220 & Halichoeres garnoti & Yellowhead Wrasse & $\mathrm{Mi}, \mathrm{Ma}$ \\
\hline 214 & Halichoeres maculipinna & Clown Wrasse & $\mathrm{Mi}, \mathrm{Ma}$ \\
\hline 217 & Halichoeres pictus & Rainbow Wrasse & $\mathrm{P}$ \\
\hline 23 & Inermia vittata & Boga & $\mathrm{P}$ \\
\hline 196 & Lutjanus apodus & Schoolmaster & Ma, F \\
\hline 194 & Lutjanus mahogoni & Mahogany Snapper & $\mathrm{Ma}, \mathrm{F}$ \\
\hline 54 & Microspathodon chrysurus & Yellowtail Damselfish & $\mathrm{H}$ \\
\hline 77 & Mulloidichthys martinicus & Yellow Goatfish & Mi \\
\hline 198 & Myripristis jacobus & Blackbar Soldierfish & $\mathrm{P}$ \\
\hline 197 & Ocyurus chrysurus & Yellowtail Snapper & $\mathrm{Ma}, \mathrm{F}$ \\
\hline 180 & Paranthias furcifer & Creole-fish & $\mathrm{P}, \mathrm{F}$ \\
\hline 156 & Scarus croicensis & Striped Parrotfish & $\mathrm{H}$ \\
\hline 149 & Scarus taeniopterus & Princess Parrotfish & $\mathrm{H}$ \\
\hline 150 & Scarus vetula & Queen Parrotfish & $\mathrm{H}$ \\
\hline 152 & Sparisoma aurofrenatum & Redband Parrotfish & $\mathrm{H}$ \\
\hline 155 & Sparisoma viride & Stoplight Parrotfish & $\mathrm{H}$ \\
\hline 51 & Stegastes diencaeus & Longfin Damselfish & $\mathrm{H}$ \\
\hline 48 & Stegastes partitus & Bicolor Damselfish & $\mathrm{P}, \mathrm{H}$ \\
\hline 53 & Stegastes planifrons & Threespot Damselfish & $\mathrm{H}$ \\
\hline 213 & Thalassoma bifasciatum & Bluehead & $\mathrm{P}, \mathrm{Mi}$ \\
\hline \multicolumn{4}{|l|}{ Cluster b } \\
\hline 337 & Acanthemblemaria maria & Secretary Blenny & $\mathrm{P}$ \\
\hline 338 & Acanthemblemaria spinosa & Spinyhead Blenny & $\mathrm{P}$ \\
\hline 205 & Acanthurus chirurgus & Doctorfish & $\mathrm{H}$ \\
\hline 35 & Apogon binotatus & Barred Cardinalfish & $\mathrm{P}$ \\
\hline 39 & Apogon maculatus & Falmefish & $\mathrm{P}$ \\
\hline 36 & Apogon townsendi & Belted Cardinalfish & $\mathrm{P}$ \\
\hline 239 & Aulostomus maculatus & Trumpetfish & $\mathrm{F}$ \\
\hline 69 & Cantherhines pullus & Orangespotted Filefish & $\mathrm{H}, \mathrm{B}$ \\
\hline 133 & Caranx rubber & Bar Jack & $\mathrm{F}$ \\
\hline 32 & Chaetodon aculeatus & Longsnout Butterflyfish & B \\
\hline 31 & Chaetodon capistratus & Foureye Butterflyfish & B \\
\hline 30 & Chaetodon striatus & Banded Butterflyfish & B \\
\hline 80 & Coryphopterus dicrus & Colon Goby & $\mathrm{H}$ \\
\hline 86 & Coryphopterus eidolon & Pallid Goby & $\mathrm{H}$ \\
\hline 95 & Epinephelus cruentatus & Gag & $\mathrm{Ma}, \mathrm{F}$ \\
\hline 93 & Epinephelus fluvus & Coney & $\mathrm{Ma}, \mathrm{F}$ \\
\hline 229 & Gerres cinereus & Yellowfin Mojarra & $\mathrm{Mi}, \mathrm{Ma}$ \\
\hline
\end{tabular}


Table 1. Continued

\begin{tabular}{|c|c|c|c|}
\hline Species code & Scientific name & Common name & Trophic level \\
\hline 431 & Gobiosoma evelynae & Sharknose Goby & Mi \\
\hline 90 & Gobiosoma horsti & Yellowline Goby & Mi \\
\hline 437 & Gobiosoma randalli & Yellownose Goby & $\mathrm{Mi}$ \\
\hline 216 & Halichoeres radiatus & Puddingwife & $\mathrm{Mi}, \mathrm{Ma}$ \\
\hline 6 & Holacanthus tricolor & Rock Beauty & B \\
\hline 200 & Holocentrus marianus & Longjaw Squirrelfish & $\mathrm{Ma}, \mathrm{F}$ \\
\hline 201 & Holocentrus rufus & Longspine Squirrelfish & $\mathrm{Mi}, \mathrm{Ma}$ \\
\hline 128 & Hypoplectrus chlorurus & Yellowtail Hamlet & $\mathrm{Ma}, \mathrm{F}$ \\
\hline 118 & Hypoplectrus puella & Barred Hamlet & Mi \\
\hline 121 & Hypoplectrus unicolor & Butter Hamlet & $\mathrm{Mi}$ \\
\hline 27 & Lactophrys triqueter & Smooth Trunkfish & B \\
\hline 192 & Lutjanus griseus & Gray Snapper & $\mathrm{Ma}, \mathrm{F}$ \\
\hline 207 & Melichthys niger & Black Durgon & $\mathrm{P}$ \\
\hline 17 & Ophioblennius atlanticus & Redlip Blenny & $\mathrm{H}$ \\
\hline 3 & Pomacanthus paru & French Angelfish & B \\
\hline 76 & Pseudupeneus maculatus & Spotted Goatfish & $\mathrm{Mi}$ \\
\hline 181 & Serranus tigrinus & Harlequin Bass & $\mathrm{Mi}$ \\
\hline 154 & Sparisoma chrysopterum & Redtail Parrotfish & $\mathrm{H}$ \\
\hline 153 & Sparisoma rubripinne & Yellowtail (Redfin) Parrotfish & $\mathrm{H}$ \\
\hline 50 & Stegastes fuscus & Dusky Damselfisk & $\mathrm{H}$ \\
\hline 230 & Sydonus intermedius & Sand Diver & $\mathrm{F}$ \\
\hline \multicolumn{4}{|l|}{ Cluster c } \\
\hline 226 & Amblycirrhitus pinos & Redspotted Hawkfish & Mi \\
\hline 109 & Anisotremus surinamensis & Black Margate & B \\
\hline 75 & Bothus lunatus & Peacock Flounder & $\mathrm{F}$ \\
\hline 72 & Cantherhines pullus & Whitespotted Filefish & $\mathrm{H}$ \\
\hline 137 & Caranx latus & Horse-eye Jack & $\mathrm{F}$ \\
\hline 2 & Centropyge argi & Cherubfish & $\mathrm{H}$ \\
\hline 163 & Diodon holocanthus & Balloonfish & $\mathrm{Ma}$ \\
\hline 166 & Diodon hystrix & Porcupinefish & $\mathrm{Ma}$ \\
\hline 59 & Equetus punctatus & Spotted Drum & $\mathrm{Ma}$ \\
\hline 62 & Gymnothorax miliaris & Goldentail Morray & Мa \\
\hline 66 & Gymnothorax moringa & Spotted Morray & $\mathrm{F}$ \\
\hline 106 & Haemulon carbonarium & Caesar Grunt & $\mathrm{Ma}$ \\
\hline 105 & Haemulon sciurus & Bluestriped Grunt & $\mathrm{Ma}$ \\
\hline 5 & Holacanthus ciliaris & Queen Angelfish & $\mathrm{B}$ \\
\hline 203 & Holocentrus adscensionis & Squirrelfish & $\mathrm{Mi}, \mathrm{Ma}$ \\
\hline 221 & Kyphosus sectatrix/incisor & Bermuda Chub/Yellow Chub & $\mathrm{H}$ \\
\hline 28 & Lactophrys bicaudalis & Spotted Trunkfish & B \\
\hline 25 & Lactophrys polygonia & Honeycomb Cowfish & B \\
\hline 19 & Malacoctenus triangulatus & Saddled Blenny & Mi, Ma \\
\hline 102 & Mycteroperca tigris & Tiger Grouper & $\mathrm{F}$ \\
\hline 228 & Opistognathus aurifrons & Yellowhead Jawfish & $\mathrm{P}$ \\
\hline 234 & Rypticus saponaceus & Greater Soapfish & Ma, F \\
\hline 178 & Scorpaena plumieri & Spotted Scorpionfish & $\mathrm{F}$ \\
\hline 182 & Serranus baldwini & Lantern Bass & $\mathrm{Mi}$ \\
\hline 185 & Serranus tabacarius & Tabaccofish & $\mathrm{Mi}$ \\
\hline 7 & Sphyraena barracuda & Great Barracuda & $\mathrm{F}$ \\
\hline
\end{tabular}

Trophic levels are defined as: H, herbivore; P, planktivore; B, browser; Mi, microinvertivore; Ma, macroinvertivore; F, piscivore.

gates at the reef crest in order to best encounter prey. It is also likely that direct and indirect behavioral interactions could exclude taxa from co-occurring within the same patch of habitat.
Carr et al. (2002) showed that negative interactions of both predators and competitors regulate local patterns of community composition. Positive interactions, on the other hand, such as those 


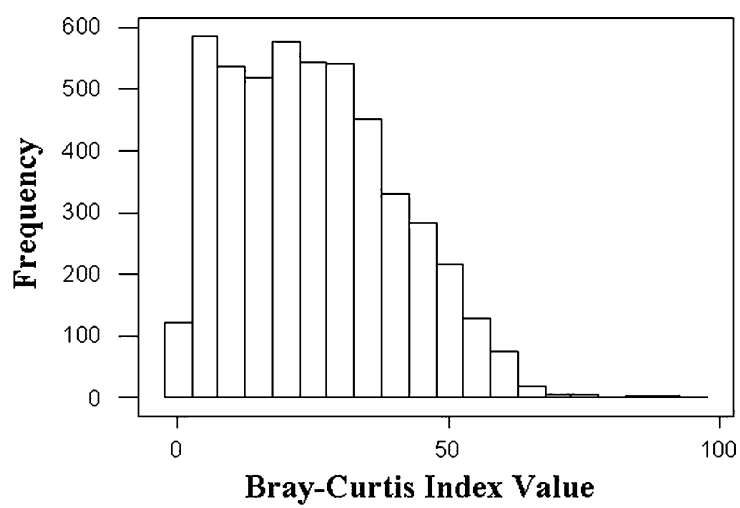

Figure 1. Distribution of Bray-Curtis coefficient values from the species similarity matrix. (Distribution by quartiles: $1-25=2724,26-50=1929,51-75=289,76-100=8$.)

found in mixed species foraging groups (Auster \& Lindholm 2002) could enhance the strength of particular species co-occurrences.

Patterns in the trends of increasing and decreasing proportions of different trophic guilds across the cluster groups, and guild membership within cluster groups, reveal directions for future research. For example, orthogonal contrasts in interspecific behavioral interactions, patterns of habitat selection, and interactions with prey populations of selected piscivores in each of the clusters (e.g., schoolmaster and mahogany snapper from cluster A; gray snapper, coney, and gag from cluster B; and tiger grouper from cluster C) could yield insights into how pairwise interactions may mediate the distribution of these taxa across reef landscapes. Patterns of species relationships revealed in the MDS plot can be used to identify species pairs and groups for further investigation. Further, contrasts in habitat use and behavioral

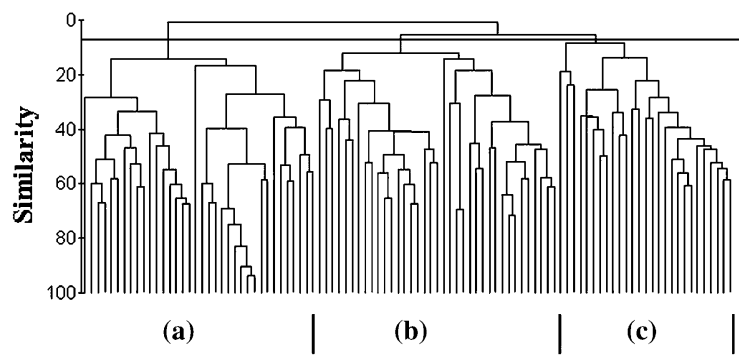

Figure 2. Dendrogram showing three distinct groups based on Bray-Curtis species similarities. Letters relate to cluster groups listed in Table 1.

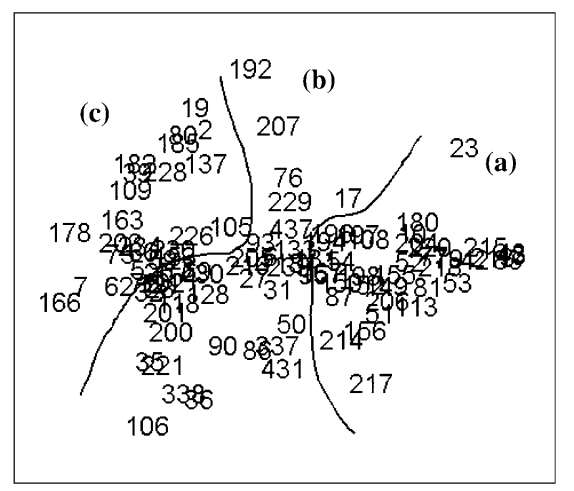

Figure 3. A two-dimensional MDS plot of the species similarity matrix (stress 0.11). Dividing lines are based on the results of the cluster analysis and illustrate a gradient of species associations across the two-dimensional space.

interactions from species-pairs composed of members from each of the distal cluster groups is a reasonable starting place to ascertain how species distributions are mediated across reef landscapes.

One approach to quantify the roles that both habitat and species-interactions play in mediating distribution and abundance is to quantify the similarity in habitat attributes where contrasting pairs of species are found. Such an approach could include samples of species composition and abundance at particular sites as well as quantification of attributes of reef habitats (e.g., coral cover, relief from seafloor, maximum current velocity) with subsequent analysis using a range of multivariate

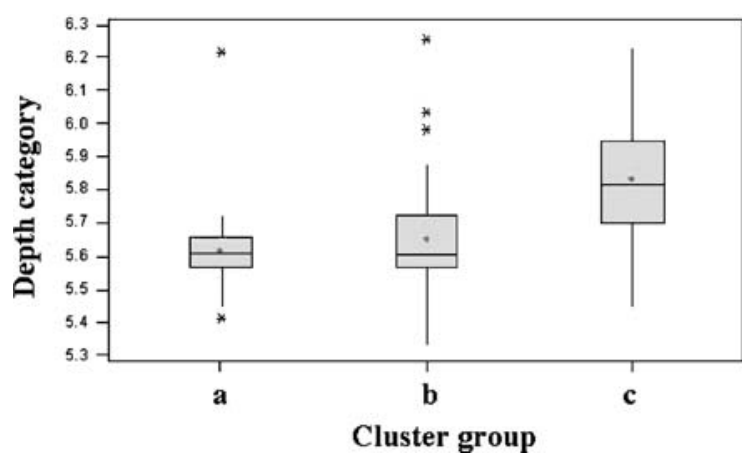

Figure 4. Box-plots of weighted average depth values for each cluster group. The center-line through each box indicates the median value and the dot indicates the mean. The top and bottom of the boxes are the top of the second and bottom of the third quartile, respectively. The top whisker marks the highest value of the top quartile and the bottom whisker marks the lowest value in the first quartile. 
Table 2. Percent representation of each trophic guild for each cluster (rounded to nearest whole number for goodness-of-fit test).

\begin{tabular}{|c|c|c|c|c|c|c|c|}
\hline & Herbivore & Browser & Planktivore & Micro-invertivore & Micro-/Macro-Invertivore & Macro-invertivore & Piscivore \\
\hline A & 36 & 3 & 33 & 6 & 8 & 6 & 8 \\
\hline B & 21 & 16 & 16 & 18 & 8 & 11 & 11 \\
\hline $\mathrm{C}$ & 12 & 15 & 4 & 12 & 8 & 27 & 23 \\
\hline
\end{tabular}

Tests of guild proportionality between clusters revealed: A vs. B: $\chi^{2}=26.68, p<0.0001$; B vs. C: $\chi^{2}=21.86, p=0.001$; A vs. C: $\chi^{2}=65.348, p<0.0001$; each comparison with $\mathrm{df}=6$.

techniques (McGarigal et al. 2000). Species pairs tending to occur at sites with high similarity in habitat attributes would then be assessed for evidence of behavioral interactions that limit cooccurring distributions of particular species pairs using observation or experimental methods.

RDT is a random swim survey protocol with area of coverage usually no greater than $100 \mathrm{~m}$ radius from the survey origin. However, survey effort (based on time as a proxy) varied between divers (for those that reported survey time; $n=797$ surveys), hence effort within each survey was not constant throughout the data set (Figure 5). A linear regression of species richness versus bottom time, while significant (ANOVA $p<0.001$, $\mathrm{df}=1,796)$ explained only $4.8 \%$ of the variation in the data. Given that we address only the top 100 most abundant species in this study, one potential explanation for the relationship between effort and species richness is that these patterns reflect real differences in species richness between sites. Nonetheless, such variation in effort could cause a switch between abundance categories and alter the similarity index of particular species pairs. However, the likelihood of a systematic bias is extremely low across such a large number of surveys.

Pattengill-Semmens (2002) reported 362 species from 77 sites based on roving diver surveys in Bonaire Marine Park. Multivariate analysis showed that fish assemblages on the main island of Bonaire were distinct from those of Klein Bonaire. Further, assemblages within the two research reserves on the main island were distinct from other Bonaire sites. Bonaire is one of the most species rich locations in the REEF database, suggesting that habitat partitioning and inter-specific interactions could be intense. Knowledge of processes that mediate small-scale distribution patterns of reef fishes could increase the precision of predictions about the performance of MPAs for maintaining representative communities, especially when populations of component species vary over time (e.g., Pinnegar et al. 2000).

While our analysis hinged on a relatively coarse observational data set, it nonetheless yielded tantalizing patterns in relationships between species of reef fishes around Bonaire. Generally, there are few spatially comprehensive data sets available for particular geographic locations other than REEF surveys. Analyses such as ours, and the type of data they are based on, clearly benefit conservation planning efforts when representation of diversity is a primary goal. Bonaire Marine Park surrounds the main island of Bonaire as well as Klein Bonaire to a depth of $60 \mathrm{~m}$ and serves as a global example of marine conservation. Hawkins et al. (1999) showed there was virtually no difference in species richness, abundance and biomass of fishes between areas opened and closed to divers within the park. However, many other sites throughout the Caribbean Basin have significant amounts of fishing and development related pressures impacting reef fish communities (e.g., Polunin \& Roberts 1993). Designating MPAs with high levels of protection to capture representative examples of local diversity may be critical for

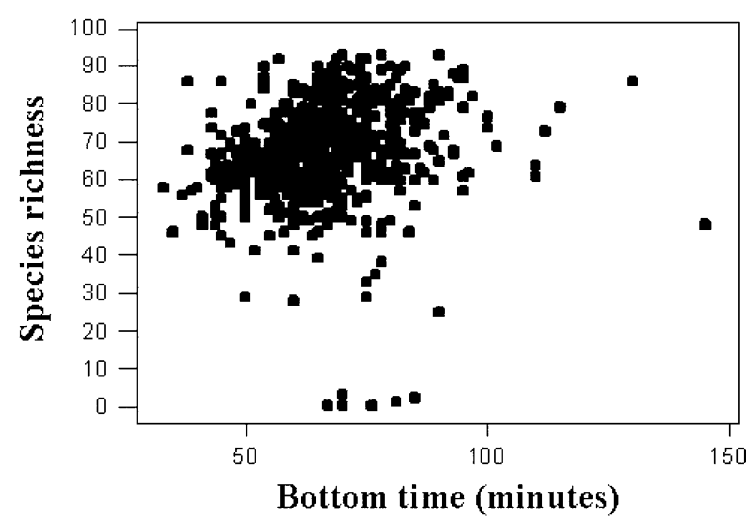

Figure 5. Plot of survey effort by divers (based on time) versus species richness. 
avoiding local extinctions (at the scale of individual islands). Studies contrasting the distribution and abundance of selected fish species have empirically demonstrated that protection of even small areas of coral reefs from fishing and other human disturbances can elicit increases in some populations within protected zones (e.g., Russ 1985, Polunin \& Roberts 1993). However, the ability to predict whether changes in the abundance of component taxa might reduce or enhance the ability of particular sites to retain co-occurring populations, based on a systematic understanding of behavioral interactions, is needed to meet long term conservation goals and improve planning for networks of MPAs.

\section{Acknowledgments}

We thank all of the divers who participated in REEF fish surveys of Bonaire. Without their dedicated effort, this study would not have been possible. PJA was supported by the National Oceanic and Atmospheric Administration's National Undersea Research Program and a Pew Marine Conservation Fellowship. BXS was supported by the Environmental Protection Agency through a STAR Fellowship. KB was funded by a Summer Undergraduate Research Fellowship from the University of Connecticut and a Summer Student Research Grant from the National Undersea Research Center. The views expressed herein are the authors and do not necessarily reflect the views of the Pew Charitable Trusts, NOAA, EPA or their subagencies.

\section{References}

Auster, P.J. \& J. Lindholm. 2002. Pattern in the local diversity of coral reef fishes versus rates of social foraging. Caribbean Journal of Science 38: 263-266.

Bohnsack, J.A., A.Y. Cantillo \& M.J. Bello. 2002. Resource survey of Looe Key National Marine Sanctuary 1983. United States Department of Commerce, NOAA Technical Memorandum NMFS-SEFSC-478: p.267.

Carr, M.H., T.W. Anderson \& M.A. Hixon. 2002. Biodiversity, population regulation, and the stability of coral-reef fish communities. Proceedings of the National Academy of Sciences 99: 11241-11245.
Clarke, K.R. \& R.N. Gorley. 2001. PRIMER v5: User Manual Tutorial. PRIMER-E, Plymouth, United Kingdom. 91 pp.

Diamond, J.M. 1975. Assembly of species communities. pp. 342-444. In: M.L. Cody \& J.M. Diamond (eds.), Ecology and Evolution of Communities, Harvard University Press, Cambridge.

Feeley, K. 2003. Analysis of avian communities in Lake Guri, Venezuela, using multiple assembly rule models. Oecologia 137: 104-113.

Garpe, K.C. \& M.C. Ohman. 2003. Coral and fish distribution patterns in Mafia Island Marine Park, Tanzania: fish-habitat interactions. Hydrobiologia 498: 191-211.

Gotelli, N.J. 2000. Null model analysis of species co-occurrence patterns. Ecology 81: 2606-2621.

Hawkins, J.P., C.M. Roberts, T. van't Hof, K. De Mayer, J. Tratalos \& C. Aldam. 1999. Effects of recreational scuba diving on Caribbean coral and fish communities. Conservation Biology 13: 888-897.

Lizaso, J.L.S., R. Goni, O. Renones, G. Charton, R. Galzin, J.T. Bayle, P.S. Jerez, A.P. Ruzafa \& A.A. Ramos. 2000. Density dependence in marine protected populations: a review. Environmental Conservation 27: 144-158.

McGarigal, K., S. Cushman \& S. Stafford. 2000. Multivariate Statistics for Wildlife and Ecology Research. SpringerVerlag, New York. 283 pp.

Pattengill-Semmens, C.V. 2002. The reef fish assemblage of Bonaire Marine Park: an analysis of REEF Fish Survey Project data. Proceedings 53rd Gulf and Caribbean Fisheries Institute 53: 591-605.

Pinnegar, J.K., N.V.C. Polunin, P. Francour, F. Badalamenti, R. Chemello, M.-L. Harmelin-Vivien, B. Hereu, M. Milazzo, M. Zabala, G. D'Anna \& C. Pipitone. 2000. Trophic cascades in benthic marine ecosystems: lessons for fisheries and protected area management. Environmental Conservation 27: 179-200.

Polunin, N.V.C. \& C.M. Roberts. 1993. Greater biomass and value of target coral-reef fishes in two small Caribbean marine reserves. Marine Ecology Progress Series 100: 167176

Randall, J.E. 1967. Food habits of reef fishes of the West Indies. Studies in Tropical Oceanography 5: 665-847.

Russ, G.R. 1985. Effects of protective management on coral reef fishes in the central Philippines. Proceedings Fifth International Coral Reef Congress 4: 219-224.

Schmitt, E.F. \& K.M. Sullivan. 1996. Analysis of a volunteer method for collecting fish presence and abundance data in the Florida Keys. Bulletin of Marine Science 59: 404-416.

Semmens, B.X. \& P.J. Auster. 2004. Analysis of Caribbeanwide reef fish data using multiple community assembly rule models Abstract. Tenth International Coral Reef Symposium, Okinawa, Japan. 222 pp.

Van Veghel, M.L.J. 1997. A field guide to the reefs of Curacao and Bonaire. Eigth International Coral Reef Symposium 1: 223-234.

Wilson, J.B. 1989. A null model of guild proportionality, applied to stratification of a New Zealand temperate rainforest. Oecologia 80: 263-267. 